Rev. Elet. em Gestão, Educação e Tecnologia Ambiental (e-ISSN: 2236-1170)

\title{
CARACTERIZAÇÃO FÍSICO-QUÍMICA DE EFLUENTES DA CARCINICULTURA E SEUS IMPACTOS AO MEIO AMBIENTE
}

\author{
Carlos Enrique Jeronimo ${ }^{1}$, Caio Pio Balbino ${ }^{2}$ \\ ${ }^{1}$ Doutorado em Engenharia Quimica. Engenheiro de Processamento de Petroleo da Petrobras. \\ c_enrique@hotmail.com \\ ${ }^{2}$ Consultor Ambiental na Qualital Eng. Ambiental. Fisioterapeuta pela UNINORTE. caio_pio18@hotmail.com
}

http://dx.doi.org/10.5902/223611706273

\section{RESUMO}

Atualmente, as regiões de mangues do estado do Rio Grande do Norte, vêm sofrendo grande devastação provocada pelo acelerado crescimento da criação de camarão no qual é explorado de forma irregular ameaçando o ecossistema e a população local. Já se apresenta um quadro crítico em termos de contaminação das águas, devastação da vegetação nativa e redução de espécies marinhas, em especial, o caranguejo). É certo, então, que a degradação dos manguezais implicará em desequilíbrio ecológico, com conseqüências imprevisíveis. Dentre os principais responsáveis, no ciclo produtivo pelos impactos ao meio ambiente, destacam-se os efluentes líquidos gerados na etapa de despesca. Esse efluente é composto na sua maioria por matéria-orgânica em decomposição (restos de rações, carcaças de animais mortos, resíduos fecais, etc), bem como, alguns agentes químicos como antibióticos e antioxidantes. Visando a redução dos problemas gerados pela destinação incorreta dessas massas de efluentes, pretende-se estudar e adequar processos de tratamento físicos, químicos e microbiológicos de forma a reduzir os impactos gerados por tais efluentes, bem como, adequando a atividade aos padrões legais de disposição de efluentes industriais.

PALAVRAS-CHAVE: carcinicultura, efluentes, caracterização e tratamento.

\section{PHYSICAL AND CHEMICAL CHARACTERIZATION OF EFFLUENT OF SHRIMP AND ITS IMPACTS TO THE ENVIRONMENT}

\begin{abstract}
Currently, the mangrove regions of the state of Rio Grande do Norte, have suffered great devastation caused by the rapid growth of shrimp farming in which it is operated improperly threatening the ecosystem and the local population. Has become quite a critical situation in terms of water contamination, destruction of native vegetation and reduction of marine species (especially crab). It is true, then, that the degradation of mangroves will result in ecological imbalance, with unpredictable consequences. Among the main culprits in the production cycle for the impacts to the environment, we highlight the effluents generated in step production. This effluent is composed mostly of raw organic decomposition (feed wastes, carcasses of dead animals, waste fecal etc.) as well as chemical agents such as antibiotics and antioxidants. Aiming to reduce problems caused by improper disposal of effluents of these masses, we intend to study and adjust treatment processes of physical, chemical and microbiological tests to reduce the
\end{abstract}


Rev. Elet. em Gestão, Educação e Tecnologia Ambiental (e-ISSN: 2236-1170)

impacts of such effluents, as well as adapting the activity to the legal standards of provision industrial effluents.

KEYWORDS: shrimp, wastewater, characterization and treatment.

\section{INTRODUÇÃO}

Um mercado com grande potencial de crescimento, assim é definida a atividade da carcinicultura (criação de camarão em cativeiro) brasileira. Nos últimos quatro anos, o segmento está em franco crescimento, principalmente no Nordeste, que concentra $97 \%$ da produção nacional, segundo dados da Associação Brasileira dos Criadores de Camarão ( $A B C C)$. No ano de 2002 o Brasil exportou 37,7 toneladas de camarão e em 2013 é que o setor gere U\$ 550 milhões de divisas. A exportação de camarão é liderada pelo Estado do Ceará, cuja pauta em 2012 equivaleu a U\$ 454 milhões, seguido pelo Rio Grande do Norte com exportação de U\$ 447 milhões e Pernambuco com U\$ 422 milhões (BRAUN, 1993; BOYD, 2003; ABCC, 2012).

Apesar de todos os aspectos economicamente favoráveis da atividade, pode-se constatar que a expansão da carcinicultura no Nordeste, mais especificamente no Rio Grande do Norte, ocorre através de sérios impactos sócio-ambientais. Existem cerca de 800 criadores, em atividade no estado, e desses apenas 453 estão licenciados pelo IDEMA-RN, órgão responsável pelo meio ambiente no estado. Isso evidencia a ausência de políticas públicas que assegurem a possibilidade das populações locais protagonizarem alternativas sustentáveis para o cultivo do camarão (IDEMA, 2012).

Outro fator importante a ser considerado no ciclo produtivo do camarão está na localização da maioria dos viveiros de produção, ou seja, nos manguezais. O mangue é um ecossistema de biodiversidade riquíssimo e apresenta um papel fundamental para a reprodução de inúmeras espécies. Segundo Matanó (2003), quando submetido a impacto ambiental, todo o ciclo de reprodução marinha é perturbado. Atualmente, as regiões de mangues do estado do Rio Grande do Norte, vêm sofrendo grande devastação provocada pelo acelerado crescimento da criação de camarão, no qual é explorado de forma irregular ameaçando o ecossistema e a população local. Já se apresenta um quadro crítico em termos de contaminação das águas, devastação da vegetação nativa e redução de espécies marinhas, em especialmente o caranguejo, conforme citam Madrid (2004) e Maia (2005).

Portanto, a degradação dos manguezais implicará em desequilíbrio ecológico, com conseqüências imprevisíveis.

Em alguns países da Ásia e América Latina, a construção indiscriminada de tanques de carcinicultura e canais de abastecimento de água representam uma redução nas áreas de manguezais que podem afetar a produtividade pesqueira da região (TURNER, 1977; CINTRÓN SCHAEFFER-NOVELLI, 1983; LAHMANN et al., 1987; SINH, 1994; HALLOWELL, 1996 e RIVIERAMONROY et al. 1999). A estrutura e a produtividade dos manguezais estão controladas, principalmente, a freqüência de inundação pelas marés, taxa de evaporação e aporte de água doce (pluvial e fluvial). Tais fatores estão diretamente relacionados à biodiversidade do ecossistema, sendo muitas espécies de importância econômica, e a alta produtividade primária e secundária (LUGO SNEDAKER, 1974; HUTCHINGS SAENGER, 1987; BALL, 1988 e COELHO-JR, 1998). $A$ atividade da carcinicultura altera estritamente essas variáveis temporais. 
Rev. Elet. em Gestão, Educação e Tecnologia Ambiental (e-ISSN: 2236-1170)

Nos últimos anos, tem se dado maior atenção à conservação dos manguezais devido a todos esses atributos, citados em Cavalcante (2003) e Lacerda (2004). No entanto, uma característica até então pouco considerada e, que também merece atenção especial, diz respeito ao papel dos manguezais na manutenção da alta diversidade biológica, estrutural e funcional da zona costeira, a despeito da reduzida diversidade de espécies vegetais típicas, quando comparada a outros ecossistemas (SOARES, 1997).

Não obstante, os aspectos ambientais das etapas de criação identificam-se inúmeros problemas nos ciclos de captura e no processamento do camarão, devido à emissão de componentes químicos, utilizados na conservação e controle de qualidade do produto, bem como, gerado uma grande quantidade de resíduos (ALBUQUERQUE, 2006), na forma de cascas, inaproveitáveis de forma direta para a fabricação de ração animal devido ao elevado conteúdo em fibras. Esses resíduos gerados pela manufatura das indústrias são enterrados ou jogados clandestinamente em rios ou no mar, ocasionando graves problemas de poluição.

Pretende-se neste trabalho contribuir para a identificação da potencialidade dos impactos provenientes da indústria de camarão sobre o ecossistema manguezal, avaliando-se os parâmetros físico-químicos dos diferentes efluentes emitidos, dentro da cadeia produtiva do camarão, bem como, os impactos que a deposição inadequada desses efluentes causam ao meio ambiente.

\section{OBJETIVOS}

O objetivo geral desse trabalho foi avaliar o poder poluente dos efluentes gerados na etapa de engorda dos camarões, tendo como base para isso a determinação de parâmetros ambientais, determinados em laboratório, que qualificam a natureza do resíduo e subsidiam dados para a escolha do tratamento mais adequado para o tratamento desse material. Nos objetivos específicos do projeto, tem-se a(o):

1. Caracterização dos principais danos ambientais observados, através do levantamento da matriz de impactos ambientais;

2. Avaliação dos pontos críticos de geração de efluentes na atividade da carcinicultura;

3. Realização das determinações físico-químicas de diferentes amostras de efluentes coletados no processo produtivo da carcinicultura, a fim de quantificar a caracterização média dos parâmetros envolvidos no tratamento de efluentes;

4. Emprego da metodologia estatística para qualificar as propriedades determinadas em laboratório e qualificar modelos matemáticos de correlação para as grandezas estudadas.

\section{METODOLOGIA}

As regiões contempladas compreendem as linhas litorâneas do município de Nísia Floresta até a região de Arês no litoral sul do estado do Rio Grande do Norte. Para a avaliação das áreas foram feitas incursões aos locais, para coleta de amostras do estuário e dos viveiros de criação dos camarões. Na Figura 1 são apresentadas imagens da área estudada.

O acompanhamento e monitoramento do ciclo de produção foram feitos no inicio do trabalho, de forma a se identificar e organizar os pontos e períodos de coleta a serem analisados.

As amostras dos efluentes de despesca foram coletadas mediante técnicas preconizadas pelas normas em vigor, obedecendo a critérios básicos de: amostragem, quantidades necessárias, conservação, prazos de validade e triplicidade nas determinações analíticas em laboratório. 


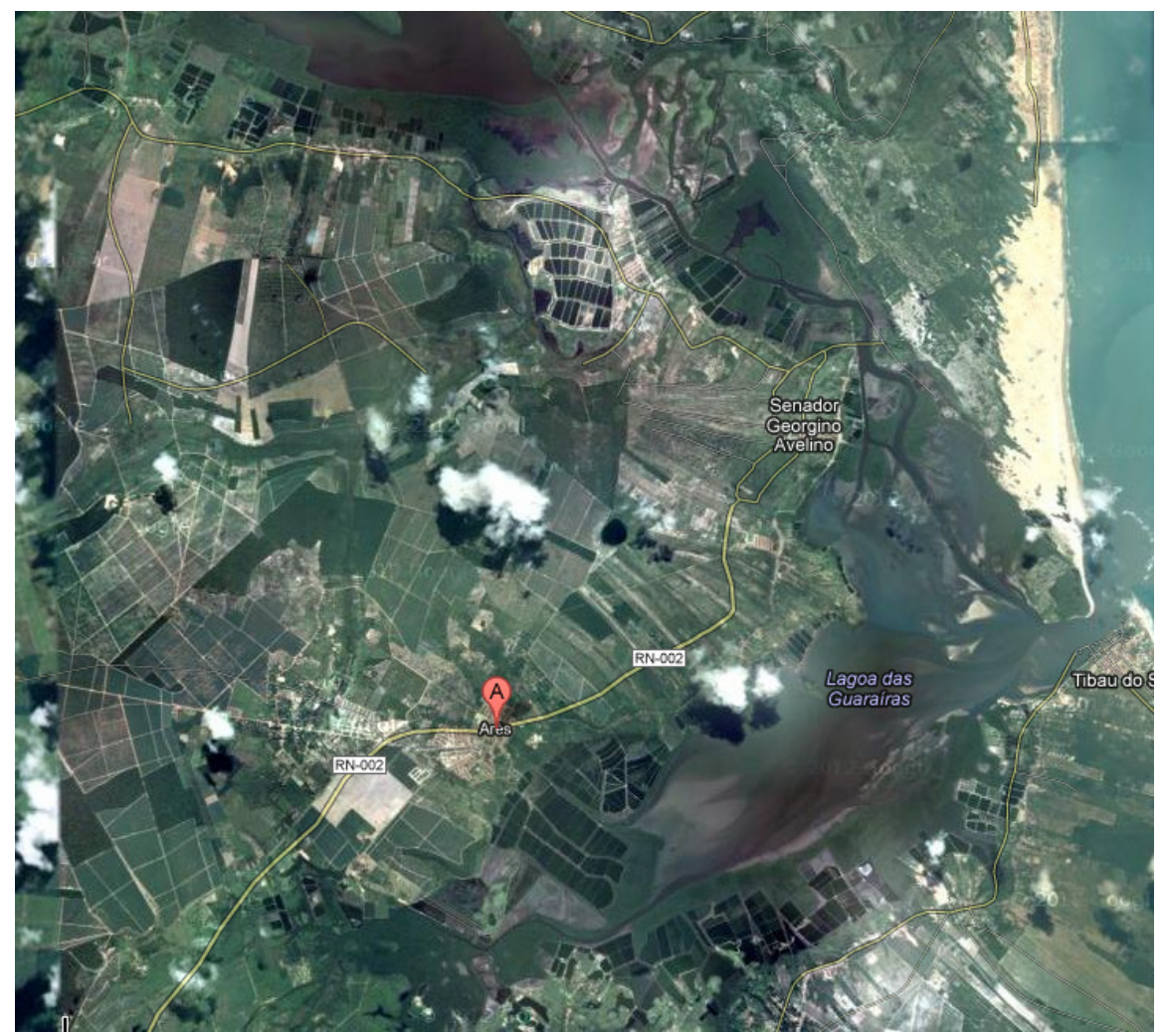

Figura 1: Viveiros de camarão da região estudada

Os parâmetros físico-químicos analisados foram: $\mathrm{pH}$, temperatura, oxigênio, condutividade, sólidos (totais, voláteis, fixos, dissolvidos, sedimentáveis e suspensos), alcalinidade, dureza, cloretos, acidez, turbidez, DBO e DQO. Os procedimentos analíticos são baseados no Standard Methods, AWWA APHA WEF (1995).

Foram estudadas as influências das variáveis operacionais nas características dos efluentes, tais como: clima, processo de engorda, ração, tempo de detenção, etc. A matriz de avaliação de impactos ambientais levantada contempla tópicos, também, de interesse econômico, social e ambiental da região, sobretudo, correlacionando as três questões e algumas séries históricas, a serem levantadas.

Foram coletadas, ainda, amostras das águas (dos corpos receptores) das regiões para caracterização analítica em laboratório por meio de parâmetros semelhantes aos utilizados para os efluentes, porém com a inclusão de parâmetros microbiológicos, indicadores de danos. Após avaliação das análises padronizou-se os defensivos utilizados e as formas mais adequadas de dispor tais efluentes na natureza, atendendo critérios mínimos exigidos pela legislação. Bem como, estudadas técnicas de sedimentação para o tratamento dos resíduos em questão. 
Rev. Elet. em Gestão, Educação e Tecnologia Ambiental (e-ISSN: 2236-1170)

\section{RESULTADOS E DISCUSSÕES}

Foram realizadas 10 bateladas de ensaios de caracterização a fim de identificar os aspectos de entrada e saída das águas coletadas no estuário da cidade de Senador Georgino Avelino-RN. Nas Figuras de 2 a 8 são apresentados os dados das dispersões das amostras coletadas.

Observa-se a estabilização dos níveis de entrada e saída, nos diferentes viveiros coletados, apresentando um regime contínuo de degeneração dos constituintes que são adicionados a estes e do próprio ciclo de vida inerente às atividades.

$\mathrm{Na}$ Figura 2, seguem os resultados no que diz respeito ao $\mathrm{pH}$, onde se observa uma pequena acidificação da água, após sua utilização no processo de engorda dos camarões. Entretanto, os índices não estabelecem restrições ao descarte nas áreas de coleta, em especial quando comparado à resolução CONAMA 430/2011.

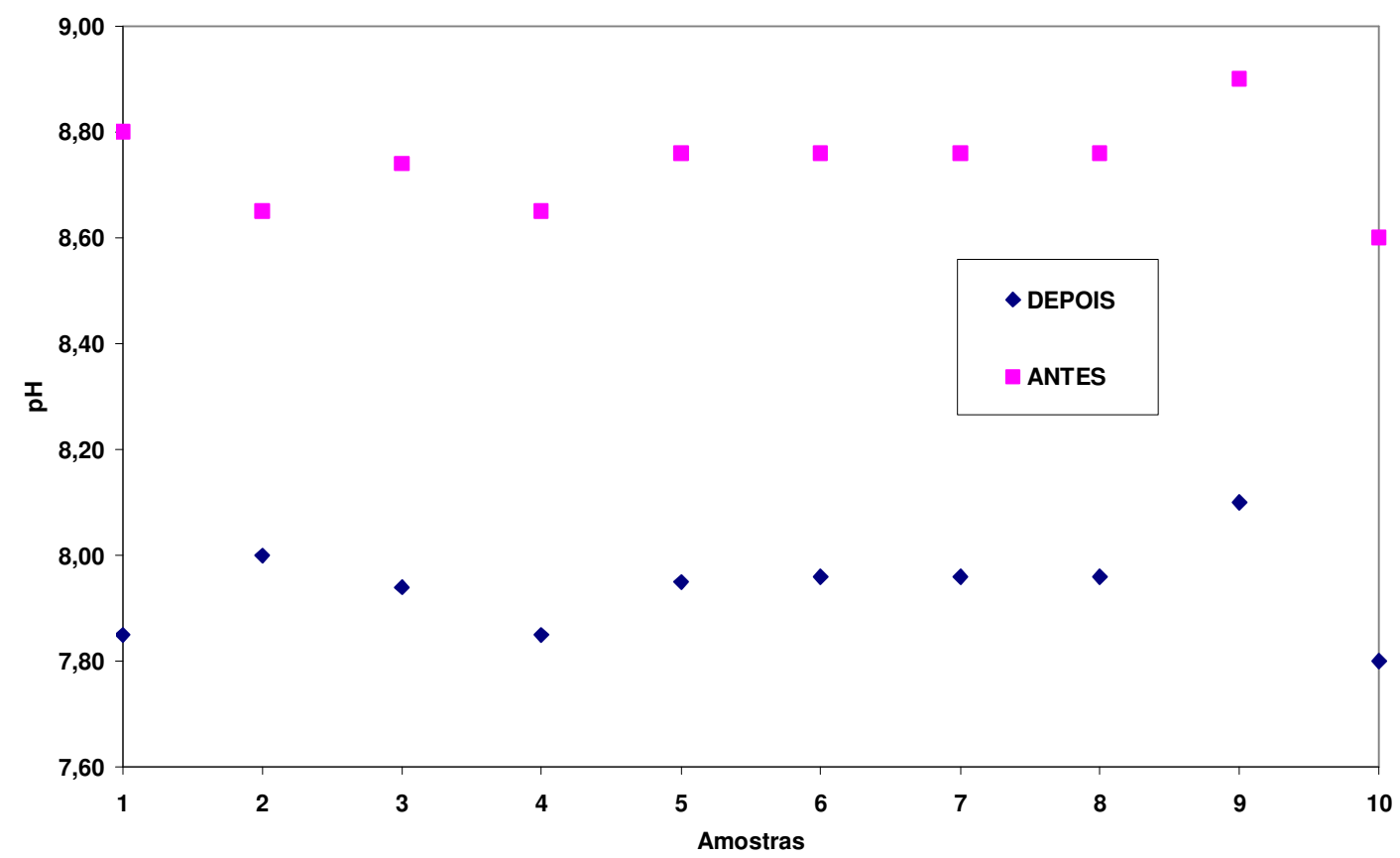

Figura 2: Dispersão dos valores para o pH das diferentes amostras analisadas

Na Figura 3, se perfazem os dados da matéria orgânica biodegradável constituinte das águas, observando um considerável aumento (cerca de 750\%). Esse aumento pode ser atribuído: às carapaças que são depositadas, aos resíduos de ração e aos outros constituintes que são agregados no processo. Em termos do regime, o comportamento foi observado em todas as amostras coletadas. Um simples ajuste de $\mathrm{pH}$ com soluções ácidas de ácido cítrico ou tanino podem corrigir tal patamares de descarte. 


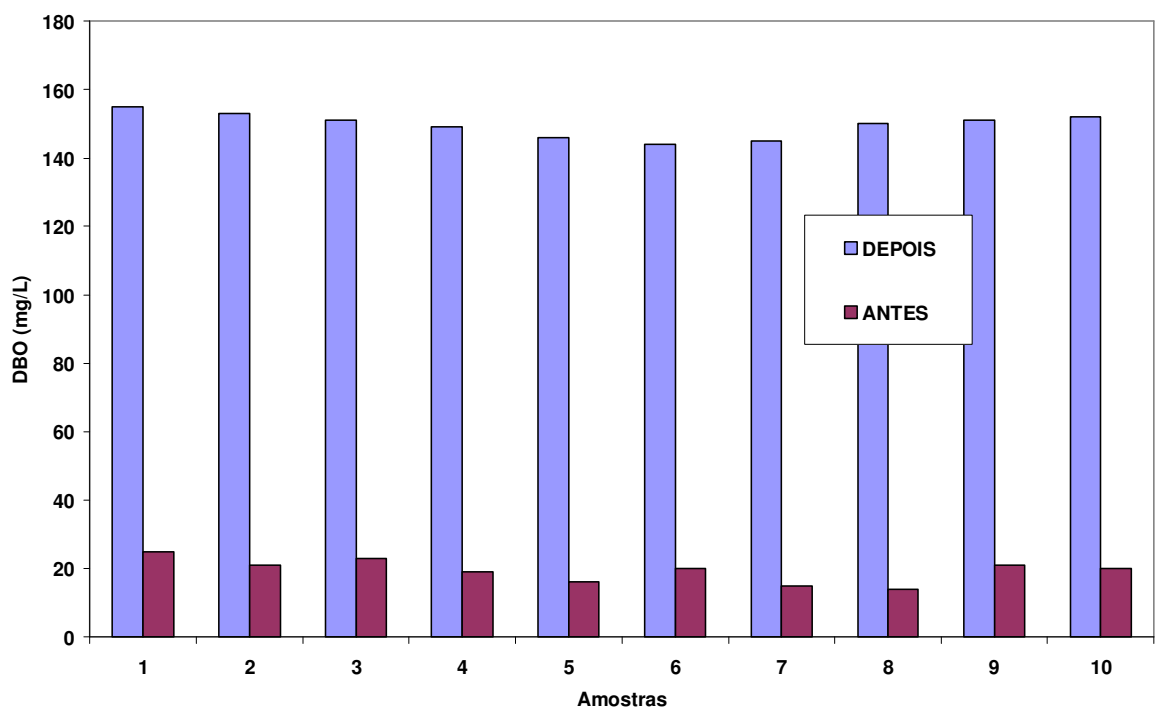

Figura 3: Dispersão dos valores para a DBO das diferentes amostras analisadas

No que diz respeito aos valores da demanda química de oxigênio (DQO), tem-se que essa se constitui do dobro da matéria orgânica biodegradável, porém, o aumento ao longo do processo não é superior a 300\% dos valores iniciais. Na Figura 4, são apresentados os valores obtidos para as amostras analisadas. Tais resultados foram semelhantes aos descritos por Albuquerque (2005) e Albuquerque et al (2006).

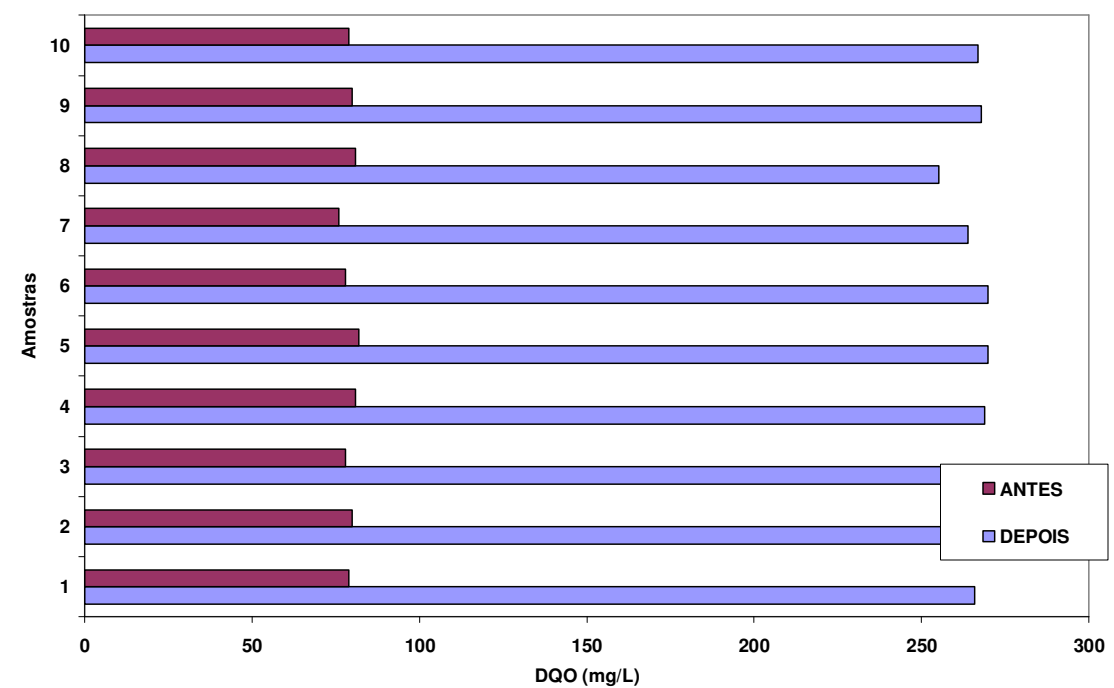

Figura 4: Dispersão dos valores para a DQO das diferentes amostras analisadas

Na Figura 5 são apresentados os resultados acerca dos sólidos suspensos (conforme metodologia APHA, 1998) presentes na entrada e saída do processo. Observa-se um regime de agregação de sólidos que na sua maioria não se solubilizam na água e acabam por sedimentar em 
locais inapropriados. O aumento é superior a $500 \%$ dos valores iniciais, tendo a adequação de um tratamento físico a satisfação para redução dos impactos advindos na atividade.

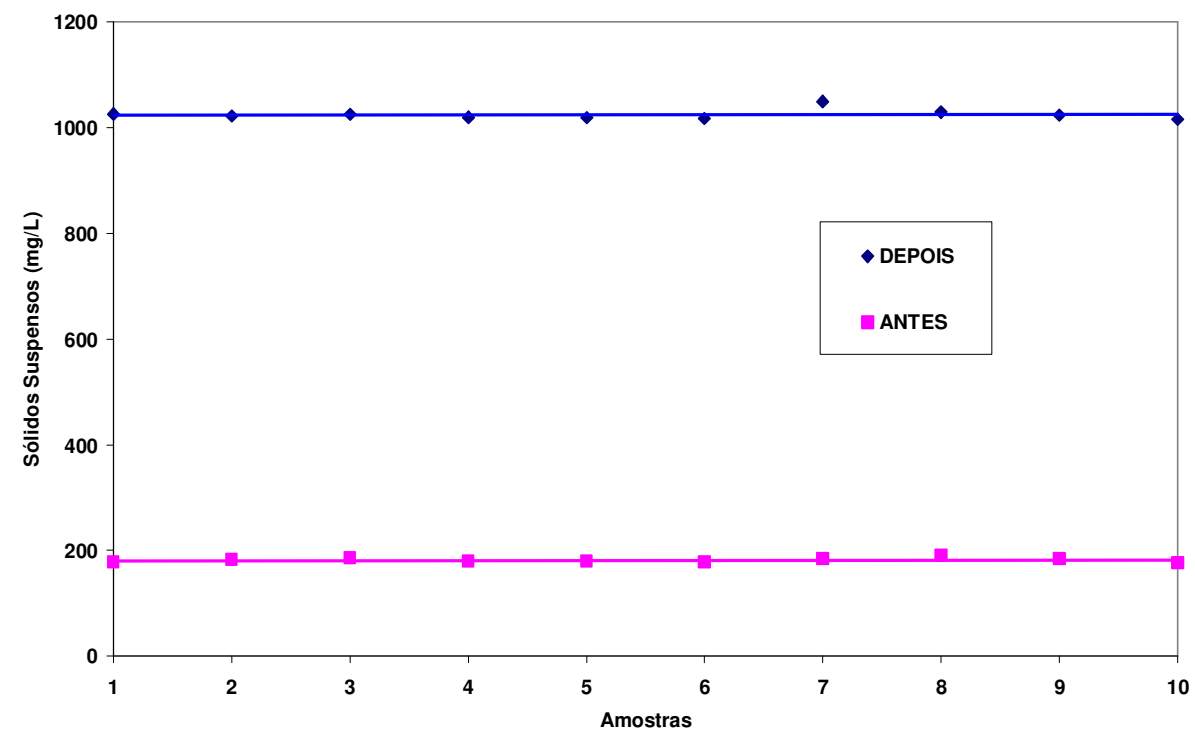

Figura 5: Dispersão dos valores para o teor de sólidos suspensos das diferentes amostras analisadas

Na Figura 6, tem-se a representação da condutividade (medida indireta da presença de íons em solução) que se eleva pela concentração dos sais, ao longo do ciclo evaporativo natural. A redução dos íons, em solução, se direciona a um abaixamento da condutividade do meio, favorecendo a proliferação de organismos específicos e reduzindo a gama de alternativas de adaptações. A dispersão desses efluentes pode reduzir o grau de salinidade e pode vir a ser prejudicial na reprodução de organismos marinhos.

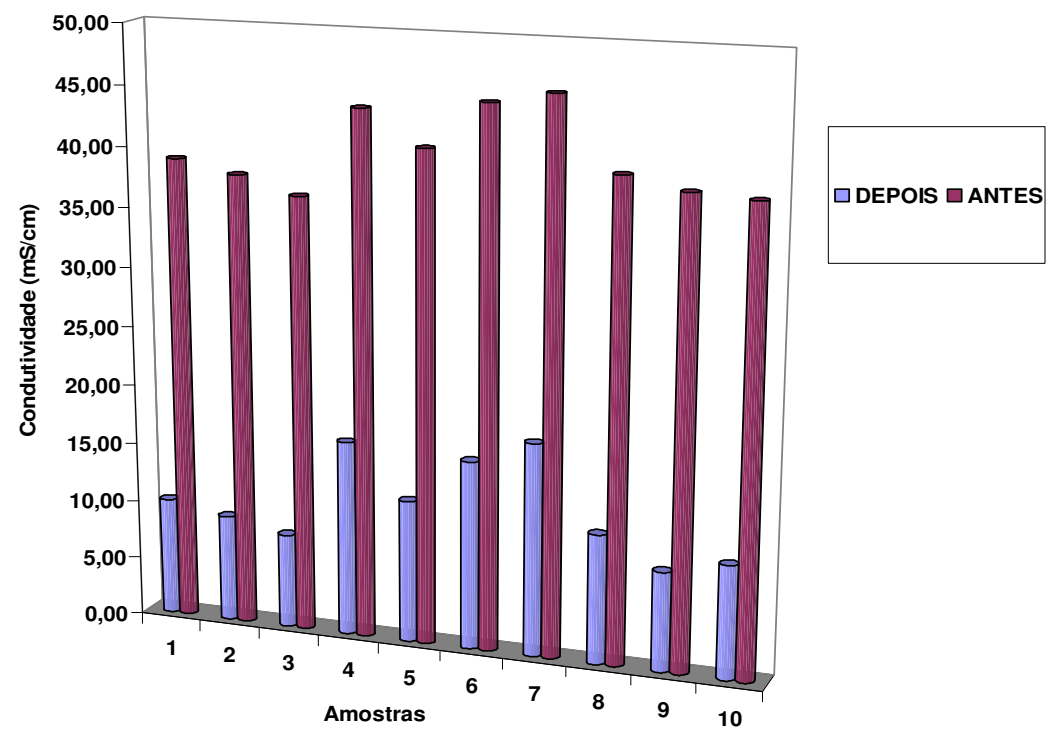

Figura 6: Dispersão dos valores para a Condutividade das diferentes amostras analisadas 


\section{anim}

JERÔNIMO \& BALBINO, v(8), n 8, p. 1639-1650, SET-DEZ, 2012.

Rev. Elet. em Gestão, Educação e Tecnologia Ambiental (e-ISSN: 2236-1170)

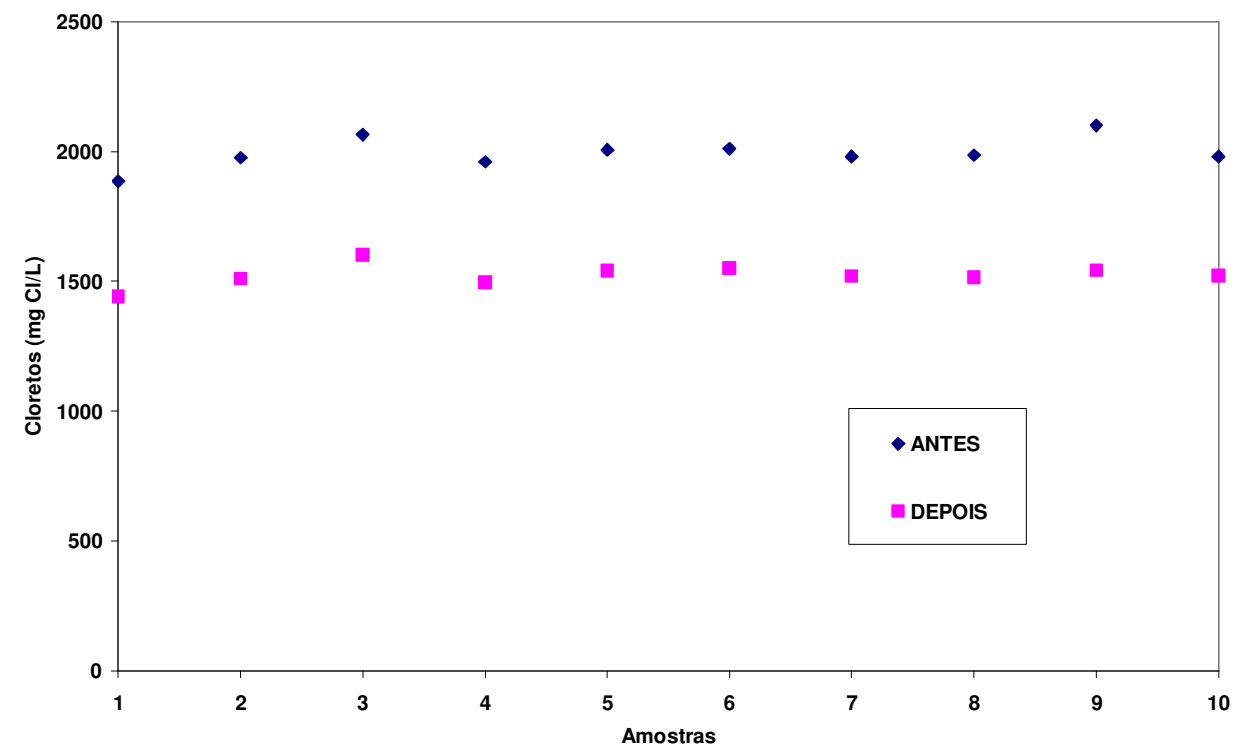

Figura 7: Dispersão dos valores para a concentração de cloretos das diferentes amostras analisadas

Na Figura 7, a redução dos parâmetros de salinidade é comprovada pela redução da concentração de íons cloretos, que se precipitam e não se compõe na fase líquida analisada nesse trabalho. Os índices evidenciados devem ser minuciosamente avaliados pelas empresas do segmento de forma que a vazão residuária não venha a ser disposta de forma conjunta, possibilitando uma diluição dos mananciais. A gestão integrada é a principal variável de controle para inibição dos impactos advindos por esse material, pelas intermitências na pressão osmótica do meio. Tal efeito é um dos pontos de atenção de Albuquerque (2005), em função da inibição dos sais no processo oxidativo avançado dos principais efluentes da indústria da carcinicultura.

A alcalinidade, representada na Figura 8, praticamente não varia ao longo do processo. A faixa das amostras analisadas oscila de 1860 a $2000 \mathrm{mg} / \mathrm{L}$. No caso da presença de componentes nitrogenados, tal nível permite o tratamento de índices superiores a $200 \mathrm{mg} / \mathrm{L} \mathrm{de} \mathrm{NH}_{3}$, no processo de autodepuração. 


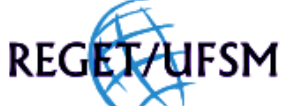

JERÔNIMO \& BALBINO, v(8), n 8, p. 1639-1650, SET-DEZ, 2012.

Rev. Elet. em Gestão, Educação e Tecnologia Ambiental (e-ISSN: 2236-1170)

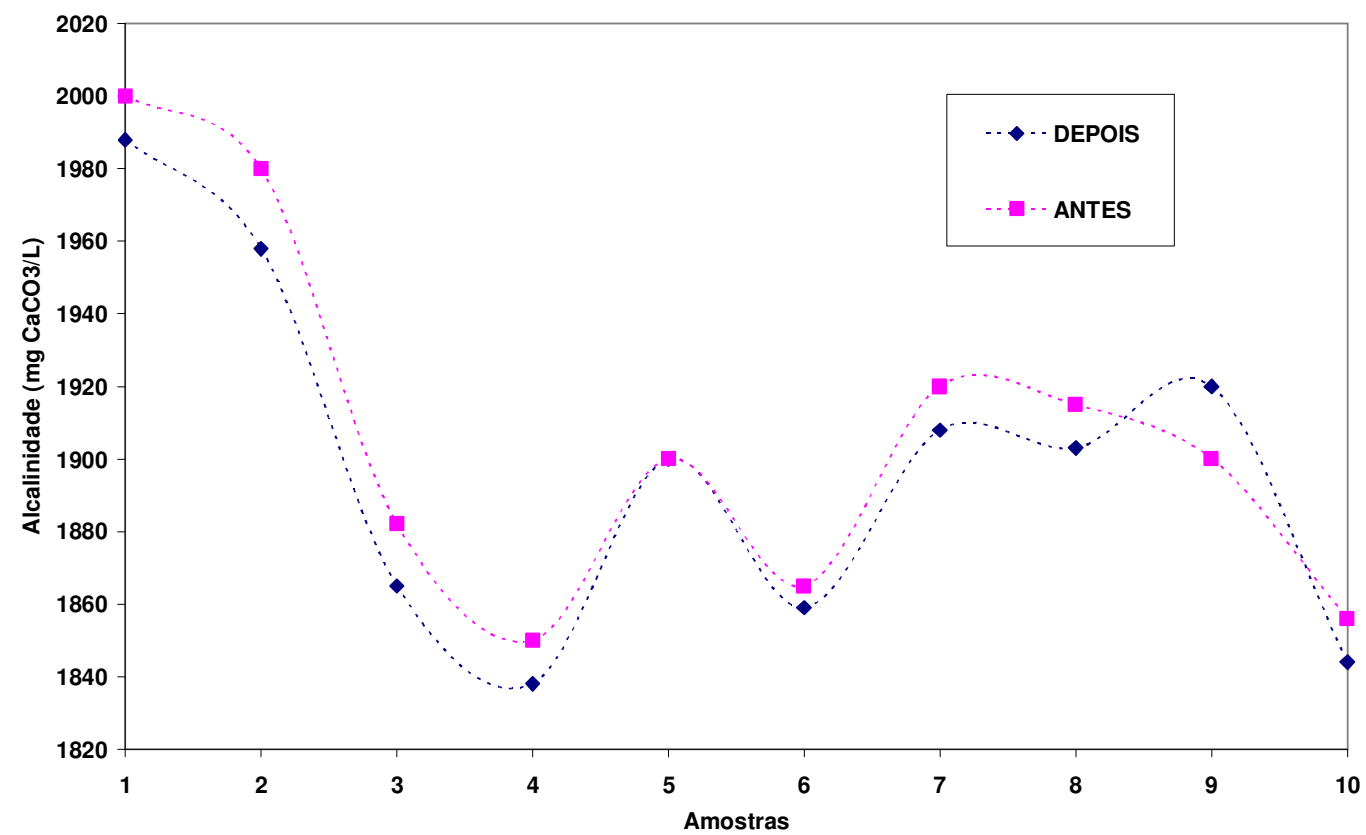

Figura 8: Dispersão dos valores para o pH das diferentes amostras analisadas

No que diz respeito aos erros experimentais, na Figura 9 é apresentado o comparativo entre as amostras analisadas. E de fato, condizem com valores dentro das expectativas descritas por Jerônimo et al (2012). Em termos de ordem de grandeza os valores estão em conformidade com os descritos por Ribeiro et al (2004), Albuquerque (2005), Albuquerque et al (2006) e Medeiros et al (2010). Em resumo, a principal problemática associada a tais efluentes está na remoção da matéria orgânica (DBO/DQO), cuja relação favorece a tratamentos biológicos, porém, precedidos de tratamento físico-químico para correção do $\mathrm{pH}$ e remoção de sólidos grosseiros. Um ponto de atenção deve ser a elevada salinidade envolvida, que poderá mitigar e inibir processos com utilização de agentes oxidativos para este efluente. 
Rev. Elet. em Gestão, Educação e Tecnologia Ambiental (e-ISSN: 2236-1170)

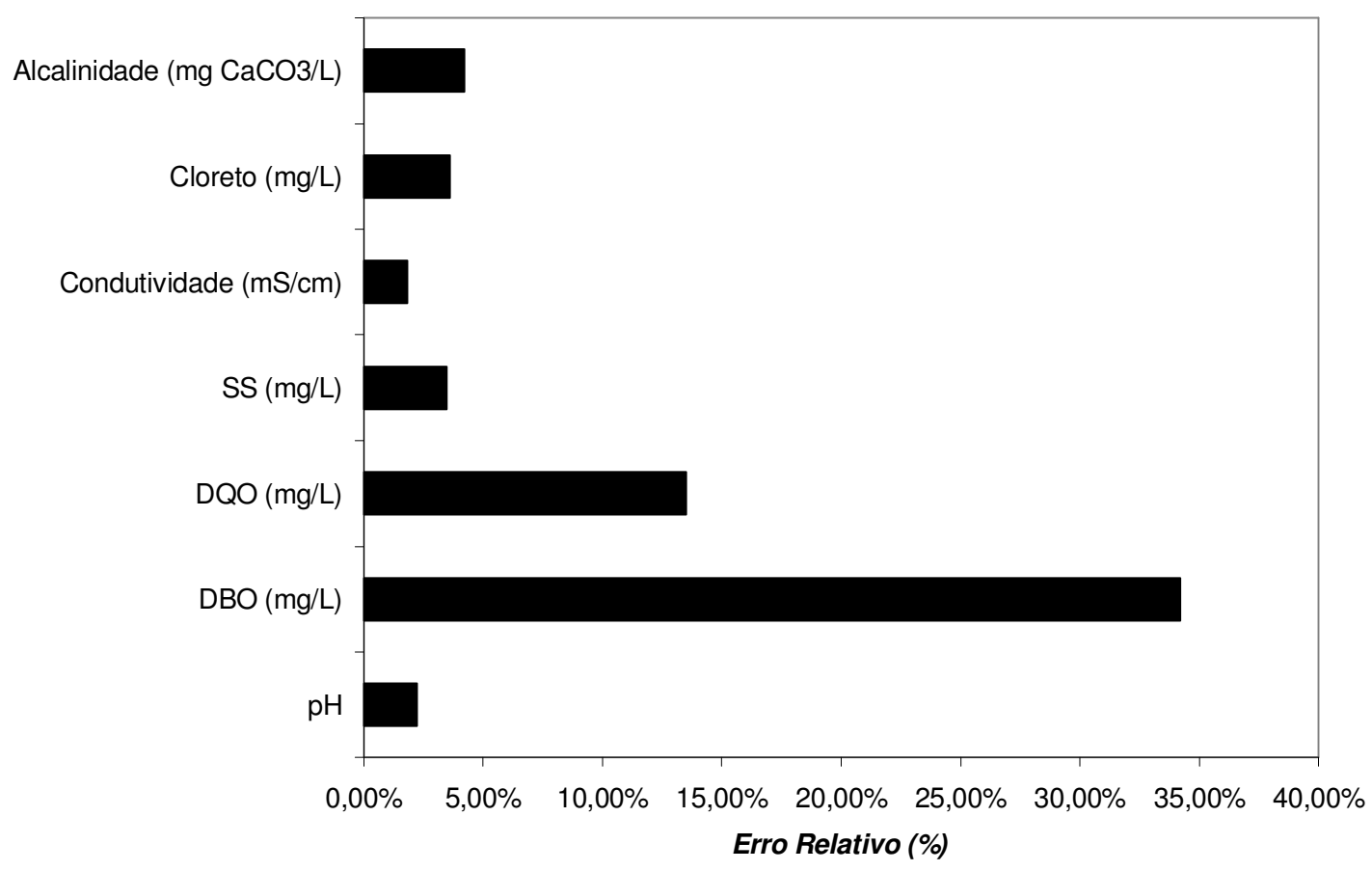

Figura 9: Erro relativo inerente às amostras analisadas.

\section{CONCLUSÕES}

A partir dos resultados pode-se concluir que:

- Existe a necessidade da inclusão de etapas de tratamento físico e biológico para a remoção dos contaminantes, mediante as concentrações de sólidos presentes nas amostras analisadas;

- O despejo das cargas residuárias deve ser monitorado e controlado, para que não cause alterações nas características das águas receptoras, visto o potencial poluidor em relação a matéria orgânica e demais componentes destas correntes;

- O impacto ao meio ambiente do despejo irregular dessas águas foi comprovado, pela discordância em 05 parâmetros, dentre os analisados, com a legislação brasileira, no caso a resolução CONAMA 430/2011.

- Foi observada diminuição do pH pelo uso de agentes químicos para eliminação de bactérias (ácidos).

- Ocorre um aumento de $750 \%$ da matéria orgânica biodegradável (resíduos das rações, carcaças etc).

- Em termos do aumento da DQO, tem-se ao longo do ciclo produtivo um aumento de 329\%.

- O aumento dos sólidos suspensos é expressivo. Direcionando para a necessidade de um processo físico de remoção. A composição desse parâmetro é derivada de carapaças, ração etc.

- A condutividade diminui no processo, pela decantação dos sais dissolvidos e consumo ao longo dos processos oxidativos do metabolismo natural da fauna e flora presente no meio. 
REGETUTFSM JERÔNIMO \& BALBINO, v(8), no 8, p. 1639-1650, SET-DEZ, 2012.

Rev. Elet. em Gestão, Educação e Tecnologia Ambiental (e-ISSN: 2236-1170)

- Há diminuição do teor de cloretos, que é ocasionada pela precipitação dos sais presentes, pela alteração do $\mathrm{pH}$ derivada dos antibióticos e outros componentes introduzidos ao processo.

- Foi observado que a alcalinidade mantém-se constante ao longo do processo.

\section{REFERENCIAS BIBLIOGRÁFICAS}

ABCC. Disponível em: http://www.abccam.com.br/abcc/. Acesso em: 20/05/2012.

AMABIS, J. M. \& MARTHO, G. R. Biologia das populações: Genética, Evolução e Ecologia. Quadro 22.2: Os manguezais. Volume 3. $1^{\circ}$ edição. 2003.

ANDRADE, S. Pesquisa quer reduzir impactos causados pela carcinicultura. Available in:http://www.tribunadonorte.com.br/anteriores/020127/natal/natal3.html. Had access in 08/27/2011.

ANDRADE, S.. Poluição está destruindo o mangue da Redinha. Available in: Had access in 08/27/2011.

APHA, AWWA, WPCF. Standard Methods for Examination for Water and Wastewater. New York: 20th ed., 1998.

BALL, M. C. 1988. Patterns of secondary sucession in a mangrove forest of southern Florida. Oecologia (Berl), 44: 226-235.

BOYD, C. E. Revista ABCC. N. 1, p. 66-71. Março, 2003.

BRAUN, A. M. et al. Advances in photochemistry. V. 18, p. 236-307. 1993.

RIBEIRO, C. M. D. et al. Simulação Sintética dos Efeitos do Metabissulfito de Sódio no Desprendimento do Oxigênio Dissolvido em Águas. VI Simpósio Brasileiro de Criadores de Camarão. 2004. Anais do Evento, Trabalho Completo.

CAVALCANTI, L. B. Variações das condições hidrológicas e da clorofila a associadas ao cultivo do camarão marinho Litopenaeus vannamei (Boone, 1931), na região estuarina do rio Paraíba do Norte (Paraíba Brasil)/. Tese de Doutorado 148 p., Recife, 2003.

CINTRÓN, G. SCHAEFFER-NOVELLI, Y. 1983. Introducción a la ecología del manglar. Oficina Regional de Ciencia y Tecnologa de la UNESCO para a America Latina y el Caribe - ROSTLAC. Montevideo-Uruguai. $109 \mathrm{pp}$.

COELHO JUNIOR, C. \& NOVELLI, Y. S. Considerações teóricas e práticas sobre o impacto da carcinicultura nos ecossistemas costeiros brasileiros, com ênfase no ecossistema manguezal. . Volume $3.1^{\circ}$ edição. 2003.

COELHO-JR, C. 1998. Manguezal, desenvolvimento estrutural da cobertura vegetal ao longo do gradiente de inundação - Cananéia, Estado de São Paulo, Brasil. Dissertação de mestrado. Instituto oceanográfico da Universidade de São Paulo. 108p.

CONAMA. CONSELHO NACIONAL DE MEIO AMBIENTE. Resolução no 430 de 13 de maio de 2011. Dispõe sobre as condições e padrões de lançamento de efluentes, complementa e altera a Resolução no 357, de 17 de março de 2005, do Conselho Nacional do Meio Ambiente - CONAMA.

HALLOWELL, C. 1996. Farmers of the sea. Time Magazine. October, 28, p.52-53.

HUTCHINGS, P. A. SAENGER, P. 1987. Ecology of mangroves. University of Queensland Press. Brisbane. 388pp.

IDEMA. Disponível em: http://www.idema.rn.gov.br. Acesso em: 11/06/2012.

JERONIMO, C. E. M. et al. Estudo comparativo entre técnicas de determinação da matéria orgânica em efluentes industriais de composição carbonácea. HOLOS, Ano 28, Vol 2. 2012. 
Rev. Elet. em Gestão, Educação e Tecnologia Ambiental (e-ISSN: 2236-1170)

LACERDA, L. D. et al. Contaminação dos metais pesados nas bacias inferiores dos rios Curimatau e Açu (RN) e rio Jaguaribe (CE) In: Impacto do ambiente Exógeno sobre a Carcinicultura Marinha. Associação Brasileira dos Criadores de Camarão (ABCC), Instituto de Ciências do Mar (LABOMAR-UFC), Sociedade Internacional para Ecossistemas de Manguezal (ISME-BR). Fortaleza, 87 p., 2004.

LAHMAN, E. J. Snedaker, S. C. Brown, M. S. 1987. Structural comparisons of mangrove forests near shrimp ponds in Southern Ecuador. Interciencia. 12(5):240-243.

LUCIO, M. M. L. M. Avaliação preliminar do efeito da carcinicultura sobre o sedimento de um trecho do Rio da Ribeira, Santa Rita-PB. Disponível em: http://bdtd.biblioteca.ufpb.br/tde_busca/arquivo.php?codArquivo=545. Acesso em: 18/06/2012.

LUGO, A. E. SNEDAKER, S. C. 1974. The ecology of mangroves. Annual Review of Ecology and Systematics, (5): 39-64.

MACEDO, L. A. A., 1986. Assimilação de esgotos em manguezais. Tese de Mestrado. Faculdade de Saúde Pública, Universidade de São Paulo, 11p.

MADRID, R. M. M., Influência do Meio Ambiente em Áreas de Risco na Qualidade Bacteriológica do Camarão Cultivado no Estado do Ceará, Projeto de Pós-Doutorado, Instituto de Ciências do Mar (LABOMAR-UFC), Fortaleza (CE), Junho de 2004.

MAIA, L. P. et al. Estudo das áreas de manguezais do nordeste do Brasil: Avaliação das áreas de Manguezais dos Estados do Piauí, Ceará, Rio Grande do Norte, Paraíba e Pernambuco. Universidade Federal do Ceará - Instituto de Ciências do Mar / Sociedade Internacional para Ecossistemas de Manguezal - ISMEBR. Fortaleza, Documento Técnico, maio de 2005.

MATANÓ, A.I et al. Estimativa das emissões de carbono, nitrogênio e fósforo para o estuário do rio Jaguaribe (CE). In: Anais do VI Congresso de Ecologia do Brasil, Pág. 163-164. Fortaleza, Documento técnico, 2003.

MEDEIROS, G. G. et al. Produção mais limpa na carcinicultura: um estudo de caso. GEPROS. Gestão da Produção, Operações e Sistemas - Ano 4, no 2, 2010, p.79-93.

NASCIMENTO, I. A. 1998. Aqüicultura marinha e ambiente: a busca de tecnologia limpa para um desenvolvimento sustentado. TECBAHIA - Revista Baiana de Tecnologia, (13) 3: 44-67.

RIVIERA-MONROY, V. H. TORRES, L. A. BAHAMON, N. NEWMARK, F. TWILLEY, R. R. 1999. The potential use of mangrove forests as nitrogen sinks of shrimp aquaculture pond effluents: the role of denitrification. Journal of the World aquaculture society. 30 (1): pp 12-25.

SINH, L.X. 1994. Mangrove forests and shrimp culture in Ngoc Hien District, Minh Hai Province, Vietnam. NAGA - The ICLARM Quarterly. 17(4):15-16.

SOARES, M.L.G. 1997. Estudo da biomassa aérea de manguezais do sudeste do Brasil - Análise de modelos. Tese de Doutorado. Instituto Oceanográfico da Universidade de São Paulo, V.1, 294pp.

TURNER, E.R. 1977. Intertidal vegetation and commercial yields of penaeid shrimp. Transactions of American Fisheries Society. 106(5):411-416. 